\title{
Cardiopulmonary Function in Very Preterm Lambs during Liquid Ventilation
}

\author{
THOMAS H. SHAFFER, ${ }^{(24)}$ NGHIA TRAN, VINOD K. BHUTANI, AND EMIDIO M. SIVIERI \\ Department of Physiology, School of Medicine Temple University Health Sciences Center, \\ Philadelphia, Pennsylvania, USA
}

\begin{abstract}
Summary
Cardiopulmonary function was evaluated in very preterm lambs (106 \pm 0.7 S.E. days gestation, $1.66 \pm 0.12$ S.E. $\mathrm{kg}$ birth weight) during fluorocarbon ventilation. Lambs were delivered by cesarean section after epidural anesthesia. Indwelling arterial, venous, and tracheal cannulae were placed before clamping the cord. Lambs were then mechanically ventilated with oxygenated fluorocarbon for approximately $2 \mathrm{~h}$. During this period it was possible to maintain adequate gas exchange and stable cardiac function. Transpulmonary pressure, liquid flow, and tidal volume tracings enabled determination of lung compliance, $C_{L}=0.58 \pm 0.12$ S.E. $\mathrm{ml} \cdot \mathrm{cmH}_{2} \mathrm{O}^{-1} \cdot \mathrm{kg}^{-1}$, inspiratory resistance, $\mathrm{R}_{\mathrm{I}}=3600 \pm 604$ S.E. $\mathrm{cmH}_{2} \mathrm{O} \cdot$ liter $^{-1} \cdot \mathrm{sec}^{-1}$, and expiratory resistance, $R_{\mathrm{E}}=4034 \pm$ 2183 S.E. $\mathrm{cmH}_{2} \mathrm{O} /$ liter/sec. Lung compliance of the 106-day-old fluorocarbon-filled lung is similar to the more mature 138-143day-old air-filled lung in preterm lambs. Based on the data presented herein we have extended the viability of the preterm lamb to the limit of pulmonary capillary development rather than that of the pulmonary surfactant system.
\end{abstract}

\section{Abbreviations}

A-a $\mathrm{DO}_{2}$, alveolar-arterial oxygen gradient $C_{L}$, lung compliance

FRC, functional residual capacity

RE, expiratory resistance

RI, inspiratory resistance

Vr, tidal volume

The lamb has been employed extensively for studying cardiopulmonary development in the perinatal period $(1,2,3,12,18$, $21)$. But there are few data in very preterm animals because cardiopulmonary stability and viability are highly correlated with maturity. The majority of studies are those in lamb fetuses at various stages of development (14), exteriorized lambs when the ewe was anesthetized $(1,5)$, or in older lambs delivered by cesarean section after 125 days of gestation $(12,18,19,21)$. Although adequate oxygen transport has been demonstrated by 110 days of gestation in exteriorized preterm fetal lambs, viability of these animals is much later (approximately 140 days, term 145-147 days).

Recent studies have revealed the feasibility of ventilation with fluorocarbon liquid in preterm lambs delivered by cesarean section between $135-138$ days gestation (17). In contrast to the respiratory problems that occur during mechanical gas ventilation $(18,19$, 21), lambs ventilated with fluorocarbon liquid exhibited good gas exchange and stable blood gas tensions. It has been suggested that the elimination of high surface forces in the liquid-filled lung could account for improved gas exchange and respiratory stability. The first objective of this study was to quantitate baseline cardiovascular, gas exchange, acid-base balance, and lung mechanics data in very immature lambs using liquid ventilation techniques. There are also apparent differences in lung mechanics between the gas and liquid-filled lungs. With this in mind, we sought to correlate these changes with the differences in physical properties of the respiratory medium.

\section{MATERIALS AND METHODS}

Animal preparation. Five preterm lambs of $106 \pm 0.7$ S.E. days gestation (70\% of term gestation) and a mean birth weight of 1.66 \pm 0.12 S.E. $\mathrm{kg}$ were studied. Before delivery, the dated ewes were restrained in a prone position, epidural anesthesia $(0.5-1.0 \mathrm{mg} / \mathrm{kg}$ of $0.75 \%$ bupivicaine $\mathrm{HCl}$ ) was induced and the uterus was exposed. Through a uterotomy, the head of the preterm lamb was allowed to emerge; inspiration was prevented by placing a rubber glove filled with warm $\left(37-39^{\circ} \mathrm{C}\right)$ saline over the head. After a local filtration of $1 \%$ lidocaine in the neck, the right carotid artery and the right jugular vein were each cannulated with appropriate sized French 5 or 8 polyvinyl catheters. An occluded cannula was inserted through a tracheotomy midway along the trachea, secured and its tip positioned proximal to the carina.

A bolus of $50 \%$ sodium bicarbonate solution $(2.5 \mathrm{ml} / \mathrm{kg})$ and a subsequent bolus of pancuronium bromide $(0.1 \mathrm{mg} / \mathrm{kg})$ were administered intravenously. Simultaneously, the animal was delivered, the rubber glove removed from the head and the umbilical cord calmped and tied. The animal was immediately connected to the liquid ventilating system.

During this period, blood was collected from the placenta in a heparinized container. The animal was dried and warmed under a radiant heat source. An intravenous crystalloid infusion (10\% dextrose with $10 \mathrm{mEq}$ sodium bicarbonate $/ 100 \mathrm{ml}$ fluid) was commenced at a rate of $3 \mathrm{ml} \cdot \mathrm{kg}^{-1} \cdot \mathrm{h}^{-1}$, and the catheters were connected to appropriate pressure transducers. Data were collected throughout the study period while the lambs under skeletal muscle paralysis (continuous administration of pancuronium bromide at $0.1 \mathrm{mg} / \mathrm{kg} / \mathrm{h}$ ) remained on the liquid ventilating system.

Liquid ventilation procedure. Liquid ventilation with fluorocarbon (RIMAR 101) was achieved using a previously described and modified liquid-breathing system. (16). Briefly, the liquid ventilation system acted as a volume ventilator in which the tidal volume, frequency, I:E ratio, and liquid flow could be adjusted. Oxygenation of the liquid and removal of carbon dioxide from the liquid was accomplished with a membrane oxygenator (Sci. Med. Life Systems, Inc., Model 3500). The temperature of the liquid was maintained at $39^{\circ} \mathrm{C}$ using an electrically controlled temperature regulator and heater (Masterline Bath and Circulator, Model 2095). The $\mathrm{PO}_{2}$ and $\mathrm{PCO}_{2}$ of the liquid were sampled from the system before and during liquid ventilation of the animal. Oxygenated liquid was removed from the liquid-breathing system and placed in a suspended reservoir. A volume equivalent to the estimated (18) functional residual capacity $(30 \mathrm{ml} / \mathrm{kg})$ of the lungs was instilled from this reservoir via the tracheotomy tube into the animal's lungs. Postural and thoracic manipulations were performed to equilibrate the fluorocarbon with prenatal lung fluid.

$\mathrm{V}_{\mathrm{T}}$ was measured by the change in the animal's weight utilizing a previously described strain gauge platform (17). This was also 
necessary to monitor the FRC and was accurate to within $1 \mathrm{ml}$ of fluorocarbon liquid. Based on previous experiments $(7,15)$ ventilation schemes were adjusted for effective carbon dioxide elimination and maintenance of physiologic arterial carbon dioxide tensions. Animals were ventilated at a mean FRC of $30 \mathrm{ml} / \mathrm{kg}$, $\mathrm{V}_{\mathrm{T}}$ of $17.9 \pm 2.0$ S.E. $\mathrm{ml} / \mathrm{kg}$, and frequency of $5.2 \pm 0.3$ S.E. breaths/min.

Experimental methods. Arterial blood gas tensions, $\mathrm{pH}$ and hematocrit were determined at $15-30$-min intervals. If the lamb's hematocrit fell below $50 \%$ as a result of blood sampling, fetal blood collected from the ewe's placenta was infused into the lamb. Blood gas and $\mathrm{pH}$ measurements were corrected to the body temperature of the animal $(10,13)$ and base deficit and percent $\mathrm{O}_{2}$ saturation were calculated. The $\mathrm{A}-\mathrm{a} \mathrm{DO}_{2}$ was determined from measured arterial blood gas tensions and estimated mean alveolar oxygen tension with the assumption that alveolar $\mathrm{PACO}_{2}$ was equivalent to $\mathrm{PaCO}_{2}$ and that the respiratory quotient was 1.0.

Cardiopulmonary measurements were conducted after the arterial blood gases and $\mathrm{pH}$ were stabilized (approximately $60 \mathrm{~min}$. postnatally). Central venous pressure and mean arterial pressure were measured by connecting the jugular vein and carotid artery catheters to the Statham P23BC and P23A transducers, respectively. Pressures were recorded on a Grass Model 7 polygraph recorder. Heart rate was obtained from blood pressure recordings. A standard limb electrocardiogram was monitored on a Cambridge VS-III EKG machine and recorded on a Grass Model 7 polygraph.

Mechanics of breathing were studied by simultaneously monitoring transpulmonary pressure, inspiratory and expiratory flow rates, and tidal volume on a Polygraph recorder (Grass Model 7) and X-Y recorder (Hewlett Packard 7035). Intraesophageal pressure was measured with an esophageal balloon, $2.5 \mathrm{~cm}$ in length and $3.0 \mathrm{~mm}$ in diameter. The balloon was filled with $0.5 \mathrm{ml}$ of air and positioned in the lower third of the esophagus. The esophageal catheter was connected to one side of a Statham PM131TC differential strain gauge transducer with a low volume adapter inserted at the inlet. Tracheal pressure was transmitted by connecting the other side of the same transducer to the side tap on the tracheal tube. The recorded signal represented an estimate of transpulmonary pressure. $\mathrm{V}_{\mathrm{T}}$ was determined from changes in weight as measured by the strain gauge platform. Liquid flow was derived by differentiating $V_{T}$ signals with a general purpose polygraph differentiator (Grass 7 P20).

Values of respiratory rate were ascertained directly from the polygraph record and dynamic lung compliance was determined graphically by the method of Neergard and Wirz (9). Lung resistance was computed by dividing the difference in transpulmonary pressure at midvolume points during inspiration and expiration by the algebraic difference in airflow at those instants. Each resistance and compliance determination was based on the average of at least three breaths. A constant tidal volume, lung volume, and frequency history preceeded all measurements.

Oxygen consumption was determined by a closed circuit spirometry method. The animal was ventilated from a liquid-filled circuit which consisted of: a spirometer to supply oxygen and to record its volume change, a Baralyme $\mathrm{CO}_{2}$ absorber to remove expired $\mathrm{CO}_{2}$, and a volume controlled liquid ventilation system (20). The system was found leak-free when tested for periods up to $2 \mathrm{~h}$. Oxygen consumption recordings were made using a wide scale strip-chart recorder (Varian, Model 9176).

The animal's rectal, esophageal, body surface, and tracheal temperatures were monitored with a digital centigrade thermometer and thermistors (Cole-Parmer, 8502-25) throughout the duration of the experiment. The source of the radiant heat was adjusted to maintain the body core temperature within a physiologic range $\left(37-39^{\circ} \mathrm{C}\right)$.

\section{RESULTS}

Liquid ventilation experiments were successfully completed in five very preterm lambs. Mean values \pm S.E.M. for prenatal carotid blood gas tensions $\left(\mathrm{PaO}_{2}=25.3 \pm 1.9 \mathrm{mmHg}, \mathrm{PaCO}_{2}=\right.$ $20.4 \pm 2.7 \mathrm{mmHg})$ and acid base status $\left(\mathrm{pH}=7.29 \pm 0.02, \mathrm{HCO}_{3}{ }^{-}\right.$ $=13.3 \pm 4.3 \mathrm{mEq} /$ liter) fell within the range previously reported in fetuses of similar gestational age (14). It has been recognized that exteriorization of the fetus leads to some differences in placental gas exchange (5).

Figure 1 illustrates sequential $\mathrm{PaO}_{2}, \mathrm{PaCO}_{2}, \mathrm{pH}$ and, rectal temperature data in lamb \#50681 after exteriorization delivery, and during $165 \mathrm{~min}$ of liquid ventilation. As shown, it took at least $30 \mathrm{~min}$ for appropriate adjustment of ventilation parameters to stabilize arterial oxygen tension and $60 \mathrm{~min}$ to overcome the initial hypothermia associated with delivery. Summarized arterial blood chemistry data for individual lambs after $1 \mathrm{~h}$ of ventilation are presented in Table 1 along with mean \pm S.E.M. values. The arterial $\mathrm{pH}$, similar to the prenatal value, was $7.29 \pm 0.2$ during liquid ventilation. A base deficit of $10.9 \pm 0.9 \mathrm{mEq} /$ liter persisted in spite of a low dose bicarbonate infusion. The gaseous exchange was significantly increased with mean oxygen saturation of over 99\%; the mean \pm S.E. arterial $\mathrm{PaO}_{2}$ was $242.5 \pm 49.4 \mathrm{mmHg}$ and was associated with an $\mathrm{A}-\mathrm{aDO} \mathrm{O}_{2}$ gradient of $415.5 \pm 50.0 \mathrm{~mm} \mathrm{Hg}$. Based on the scheme of ventilation used, $\mathrm{PaCO}_{2}$ was maintained at $30.8 \pm 1.0 \mathrm{mmHg}$. The oxygen consumption was measured to range from $5.4-8.3 \mathrm{ml} \cdot \mathrm{kg}^{-1} \cdot \mathrm{min}^{-1}$ between $30-90 \mathrm{~min}$ postnatal age.

Representative tracings of cardiopulmonary data after one hour of liquid ventilation are illustrated in Figure 2. Mean arterial

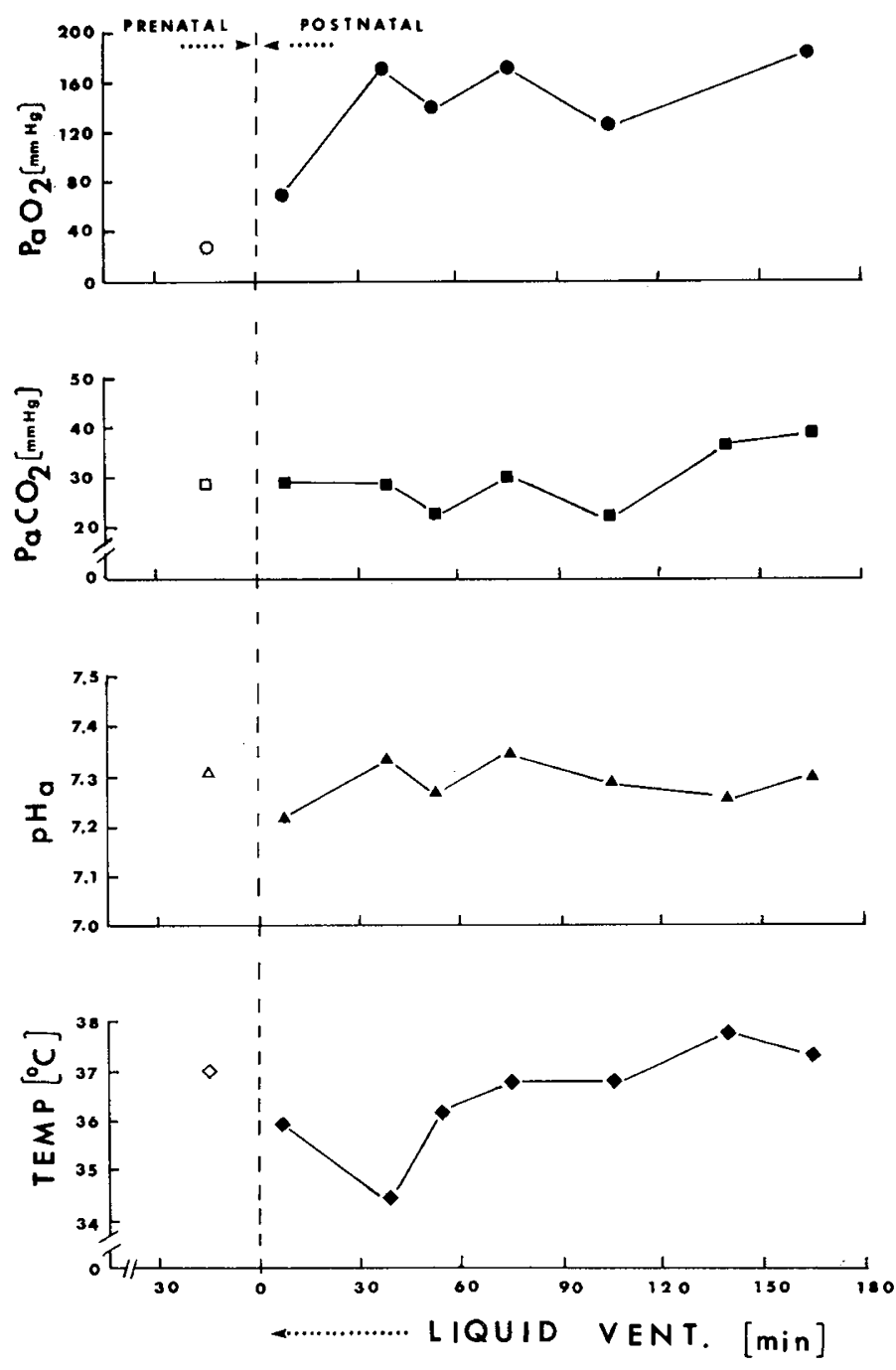

Fig. 1. Sequential values of arterial oxygen tension $\mathrm{PaO}_{2}$, carbon dioxide tension $\mathrm{PaCO}_{2}, \mathrm{pHa}$, and rectal temperature in lamb \#50681 after exteriorization, delivery, during $165 \mathrm{~min}$ of liquid ventilation. 
Table 1. Arterial blood chemistry data

\begin{tabular}{|c|c|c|c|c|c|c|c|}
\hline $\begin{array}{c}\text { Lamb } \\
\text { no. }\end{array}$ & $\begin{array}{c}\mathrm{PO}_{2} \\
(\mathrm{mmHg})\end{array}$ & $\begin{array}{c}\mathrm{PCO}_{2} \\
(\mathrm{mmHg})\end{array}$ & $\mathrm{pH}$ & $\begin{array}{l}\text { Base deficit } \\
\text { (meq/liter) }\end{array}$ & $\begin{array}{c}\mathrm{PIO}_{2} \\
(\mathrm{mmHg})\end{array}$ & $\begin{array}{r}\mathrm{A}-\mathrm{aDO} \mathrm{O}_{2} \\
(\mathrm{mmHg})\end{array}$ & $\begin{array}{c}\text { Saturation } \\
(\%)\end{array}$ \\
\hline 52281 & 145 & 32 & 7.31 & 9.4 & 650 & 505 & 98.7 \\
\hline 51281 & 314 & 29 & 7.27 & 12.6 & 710 & 396 & 99.6 \\
\hline 22380 & 340 & 33 & 7.25 & 12.3 & 622 & 282 & 99.7 \\
\hline 50681 & 171 & 29 & 7.34 & 9.2 & 650 & 479 & 99.1 \\
\hline Mean & 242.5 & 30.8 & 7.29 & 10.9 & 658 & 415.5 & 99.3 \\
\hline \pm S.E. & \pm 49.4 & \pm 1.0 & \pm 0.02 & \pm 0.9 & \pm 18 & \pm 50.0 & \pm 0.2 \\
\hline
\end{tabular}
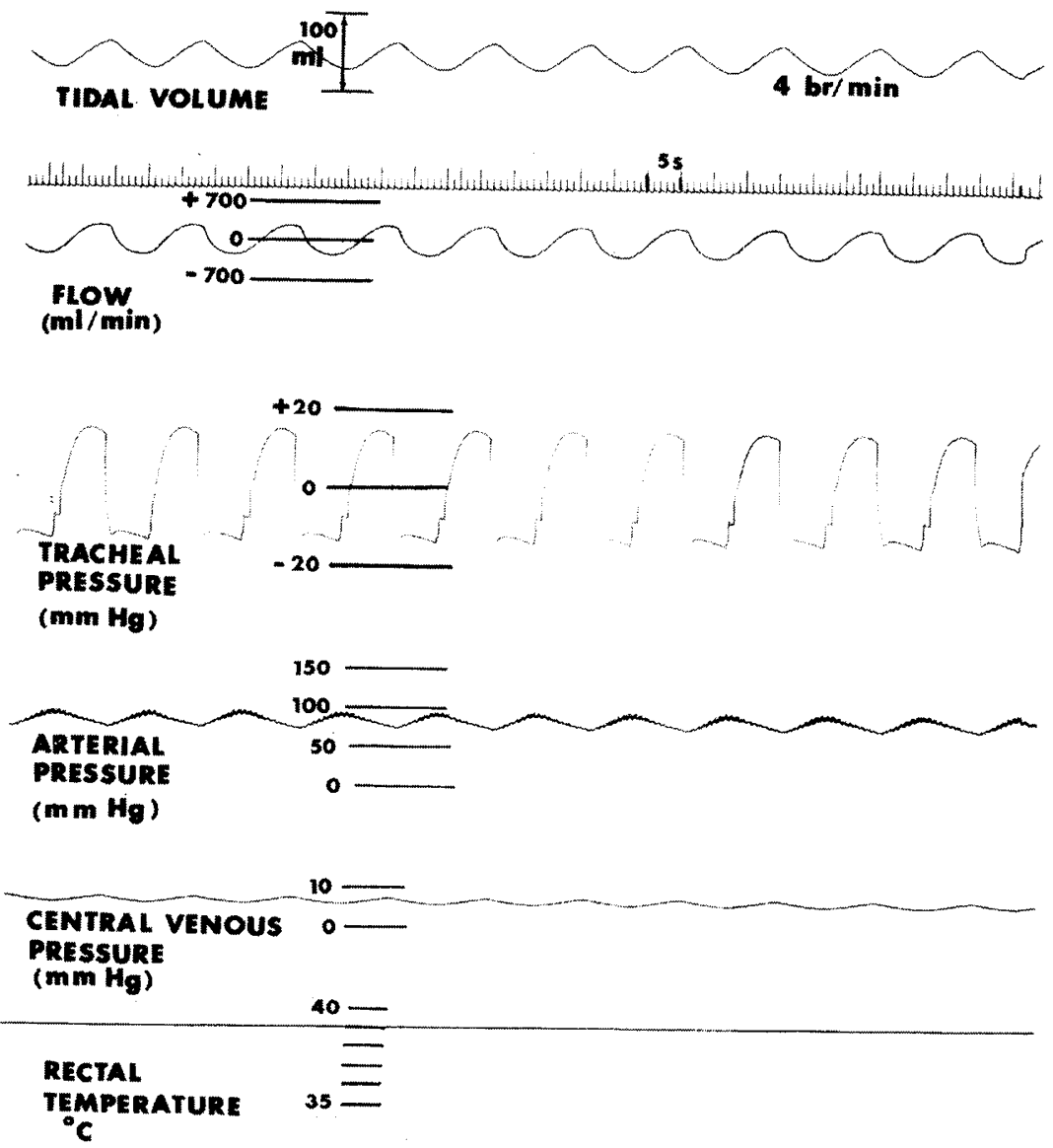

EKO

Fig. 2. Representative tracing of cardiopulmonary data during liquid ventilation in lamb \#50681 at 60 min after birth.

Table 2. Liquid ventilation data

\begin{tabular}{cccccc}
$\begin{array}{c}\text { Lamb } \\
\text { no. }\end{array}$ & $\begin{array}{c}\text { Tidal volume } \\
(\mathrm{ml})\end{array}$ & $\begin{array}{c}\text { Frequency } \\
\text { (breath/min) }\end{array}$ & $\begin{array}{c}\text { Flow } \\
(\mathrm{ml} / \mathrm{sec}) \\
\text { I/E }\end{array}$ & $\begin{array}{c}\text { Tracheal } \\
\text { pressure }(\mathrm{mmHg}) \\
\text { I/E }\end{array}$ & $\begin{array}{c}\text { I/E } \\
\text { Ratio }\end{array}$ \\
\hline 52281 & 11.6 & 5.0 & $3.6 / 2.3$ & $31.5 /-2.7$ & 0.61 \\
52081 & 23.1 & 5.0 & $5.1 / 5.1$ & $36.9 /-2.8$ & 1.0 \\
51281 & 21.0 & 4.0 & $4.7 / 4.7$ & $22.0 /-15.0$ & 1.0 \\
22380 & 16.0 & 6.0 & $8.0 / 3.2$ & $34.0 /-25$ & 0.40 \\
50681 & 17.6 & 6.0 & $10.0 / 6.7$ & $15.0 /-5.5$ & 0.67 \\
Mean & 17.9 & 5.2 & $6.3 / 4.4$ & $27.9 /-10.2$ & 0.74 \\
\pm S.E. & \pm 2.0 & \pm 0.3 & $\pm 1.1 / \pm 0.8$ & $\pm 4.1 / \pm 4.3$ & \pm 0.12 \\
\hline
\end{tabular}

pressure was $58 \mathrm{mmHg}$ with a gradual decrease during the course of the experiment. The central venous pressure and heart rate remained relatively stable during the experiments with mean values of $7.9 \mathrm{mmHg}$ and $156.5 \mathrm{beat} / \mathrm{min}$, respectively.
Steady state ventilation data for individual animals are shown in Table 2 and are associated with the blood chemistry data in Table 1. It is noteworthy that inspiratory and expiratory tracheal pressures were only 27.9 and $-10.2 \mathrm{mmHg}$, respectively, for the 
given ventilation schemes. Dynamic pressure-volume loops were obtained in three lambs and a typical curve (lamb \#50681) is shown in Figure 3. Characteristic hysteresis is described during inspiration and expiration. The values of dynamic compliance, inspiratory, and expiratory resistance are tabulated in Table 3.

Gross postmortem examination following elective termination of the experiment were conducted on all lambs. These did not exhibit any evidence of fluid or air leaks in the pleural cavity, pulmonary hemorrhage, or non-homogeneous ventilation.

\section{DISCUSSION}

Stable gas exchange, acid base status, and pulmonary function have been previously demonstrated in distressed preterm lambs (135-138 days of gestation) ventilated with oxygenated fluorocarbon liquid (17). The applicability of this procedure has been extended in the present study to include very preterm lambs of 106 days gestation. Unlike the previous studies, the fetal lambs were delivered without breathing gas and the respiratory tract was filled with warm, oxygenated fluorocarbon liquid. Hypoxemia and cold stress were thus minimized during the stage of transitional neonatal circulation.

Born et al. (1) investigated gas transport and pulmonary circulation in exteriorized preterm lambs at various stages of gestation and in isolated preterm lung preparations. These studies demonstrated that pulmonary blood flow is not sufficient to maintain adequate gas exchange in lambs of less than 105-110 days gestation. In addition they suggested that the pulmonary capillaries are sufficiently developed by 110 days gestation to provide total oxygen transport at a developmental age when the lungs remain unable to sustain normal gas ventilation. In the present study we were able to experimentally confirm Born's speculation and establish effective pulmonary oxygen transport for approximately $2 \mathrm{~h}$ in 106-day-old preterm lambs that were ventilated with oxygenated fluorocarbon liquid. It is noteworthy that these lambs did not receive augmented umbilical circulation (5) during the liquid ventilation procedure and that total oxygen and carbon dioxide

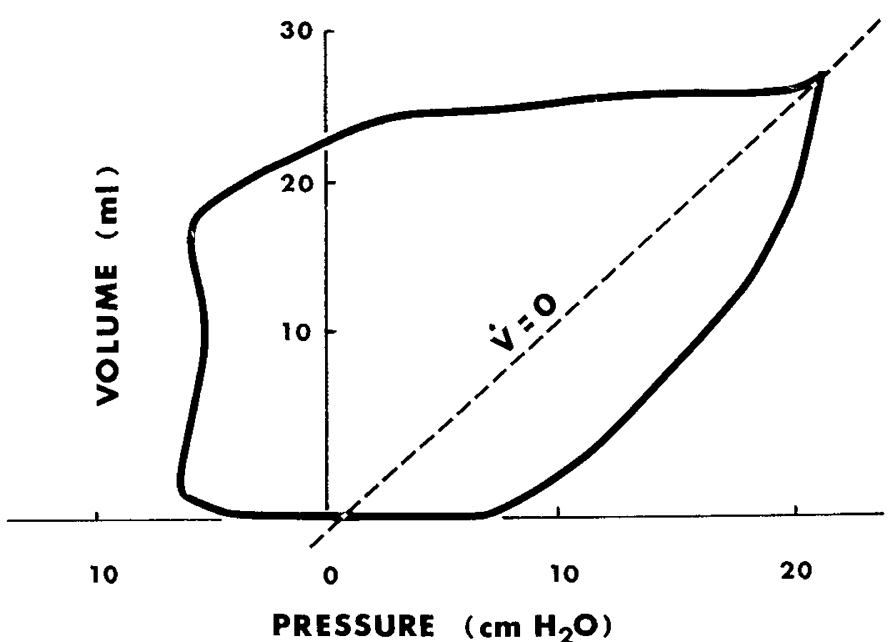

Fig. 3. Dynamic pressure-volume loop during liquid ventilation. (V, liquid flow rate). transport were due to pulmonary gas exchange.

The onset of neonatal circulation has also been associated with an increase in oxygen consumption (4). Our lambs were maintained in a neutral thermal environment with the aid of external heat (lamp) and internal heat (warmed fluorocarbon liquid). Monitoring of the core temperature through the esophagus, trachea, and rectum indicated body temperature was maintained about $38^{\circ} \mathrm{C}$. The oxygen consumption ranged from $5.4-8.3 \mathrm{ml}$. $\mathrm{kg}^{-1} \cdot \mathrm{min}^{-1}$ and is higher than in utero fetal levels of $4-5 \mathrm{ml} \cdot \mathrm{kg}^{-1}$. $\mathrm{min}^{-1}$ at comparable gestational age $(2,3)$. Postnatal rise in $\mathrm{O}_{2}$ consumption has been observed in newborn lambs with active muscle tone secondary to spontaneous ventilation and ranges from $6-8.5 \mathrm{ml} \cdot \mathrm{kg}^{-1} \cdot \mathrm{min}^{-1}(2)$. In spite of the adequate oxygen consumption we observed an ongoing mild metabolic acidosis. This degree of metabolic acidosis has been previously observed both in preterm lambs and neonates with respiratory distress $(12,18,21)$.

In the past it has been extremely difficult to deliver and keep animals alive at this early stage of gestation because both the anatomical development of alveoli and biochemical development of the surfactant system are incomplete. Using the presently described ventilation technique it appears possible to effectively maintain stable pulmonary gas exchange in an immature animal model. A more striking feature was the finding that gas exchange and lung compliance in the very preterm lambs (106 days gestation) during liquid ventilation is very similar to that in the more mature lambs (132-138 days gestation) during conventional gas ventilation (18).

The effectiveness of liquid ventilation in the very preterm lambs could involve several mechanisms. The air-liquid alveolar interface is abolished in the liquid-filled lung, thereby reducing high surface forces and possibly eliminating nonuniform ventilation which exists in the premature gas ventilated lung. Studies have demonstrated that pulmonary blood flow in the liquid-filled lung is more evenly distributed than in the gas-filled lung (22). This may be particularly significant in distressed preterm lambs that exhibit extensive intrapulmonary shunting and elevated pulmonary vascular resistance (23).

Early investigators (1) found it necessary to inflate the lungs of mature living fetuses to pressures of $20-40 \mathrm{mmHg}$ before adequate ventilation was achieved. In preterm lambs of less than 110 days gestational age, inflation was even more difficult (approximately 4-fold increase in peak inflation pressure) typically resulting in extra-alveolar leaks. In contrast to gas ventilation, the mean peak tracheal pressure required for adequate liquid ventilation was low $(27.9 \mathrm{mmHg})$. These low pressures were accomplished in spite of elevated airway resistance (increased by the viscosity and density of fluorocarbon liquid) by utilizing slow breathing and flow rates.

In conclusion, this study demonstrates that it is possible to maintain good gas exchange in very preterm lambs during normothermic liquid ventilation. Furthermore, the secondary effects of improved ventilation and pulmonary blood flow could, in the long run, facilitate surfactant synthesis. One might question whether this form of ventilation may have a long-term deleterious effect on the developing newborn lung, but we cannot directly address these issues. It is noteworthy that long-term experiments in adult dogs $(6,8,11)$ indicated scant morphologic, biochemical, and/or histologic evidence of toxicity after ventilation with fluorocarbon liquid.

Table 3. Pulmonary mechanics on liquid ventilation

\begin{tabular}{ccccc}
\hline $\begin{array}{c}\text { Lamb } \\
\text { no. }\end{array}$ & $\begin{array}{c}\mathrm{FRC}^{1} \\
(\mathrm{ml} / \mathrm{kg})\end{array}$ & $\begin{array}{c}\text { Compliance } \\
\left(\mathrm{ml} \cdot \mathrm{cm} \mathrm{H}_{2} \mathrm{O}^{-1} \cdot \mathrm{kg}^{-1}\right)\end{array}$ & $\begin{array}{c}\text { Inspiratory } \\
\text { resistance } \\
\left(\mathrm{cm} \mathrm{H}_{2} \mathrm{O} \cdot \mathrm{liter}^{-1} \cdot \mathrm{sec}^{-1}\right)\end{array}$ & $\begin{array}{c}\text { Expiratory } \\
\text { resistance } \\
\left(\mathrm{cmH}_{2} \mathrm{O} \cdot \mathrm{liter}^{-1} \cdot \mathrm{sec}^{-1}\right)\end{array}$ \\
\hline 52281 & 30 & 0.36 & 4140 & 8340 \\
51281 & 30 & 0.61 & 4268 & 1255 \\
50681 & 30 & 0.78 & 2394 & 2507 \\
Mean & & 0.58 & 3600 & 4034 \\
\pm S.E. & & \pm 0.12 & \pm 604 & \pm 2183 \\
\hline
\end{tabular}

${ }^{1}$ FRC, functional residual capacity. 


\section{REFERENCES AND NOTES}

1. Born, G. V. R., Dawes, G. S., and Mott, J. C.: The viability of premature lambs. J. Physiol., 130: 191 (1955).

2. Cross, K. W., Dawes, G. S., and Mott, J. C.: Anoxia, oxygen consumption and cardiac output in newborn lambs and adult sheep. J. Physiol, 146.316 (1959).

3. Dawes, G. S. and Mott, J. C.: The increase in oxygen consumption of the lamb after birth. J. Physiol., 146: 295 (1959).

4. Dawes, G. S.: Foetal and Neonatal Physiology. p. 110 (Yearbook Medical Publishers, Inc., Chicago, 1968).

5. Heyman, M. A. and Rudolph, A. M.: Effect of exteriorization of the sheep fetus on it cardiovascular function. Circ. Res. 21: 741-747, 1967.

6. Holiday, D. A. and Modell, J. H.: Uptake and distribution in the dog of an inert fluorocarbon, FX-80. Fed. Proc., 29: 684 (1970).

7. Koen, P. A., and Shaffer, T. H.: The effect of breathing patterns on $\mathrm{CO}_{2}$ elimination during liquid ventilation. Fed. Proc. (Abstract), 37:3434 (1978).

8. Modell, J. G., Tham, M. K., Modell, J. H., Calderwood, H. W., and Ruiz, B. C.: Distribution and retention of fluorocarbon fluid in mice and dogs after injection or liquid ventilation. Toxicol. Appl. Pharmacol., 26: 86 (1973).

9. Neergaard, K. and Wirz, K.: Über eine Methode Zur Messung der Lungenelastizität am lebenden Menschen, inbesondere bein Emphysem 1. Klin. Med. 105: 35 (1927).

10. Nunn, J. F., Bergman, N. A., Sunatyan, A., and Coleman, A. J.: Temperature coefficients for $\mathrm{PCO}_{2}$ and $\mathrm{PO}_{2}$ of blood in vitro. J. Appl. Physiol. (1965).

11. Patel, M. J., Syanto, P., Yates, H., and Long, D. M.: Survival and histopathologic changes in lungs of hamsters following synethetic liquid breathing. Fed. Proc., 29: $1742(1970)$

12. Reynolds, E. O. R., Jacobson, H. N., Motoyama, E. K., Yikkawa, Y., Craig, J. M., Orzalesi, M. M., and Cook, C. D.: The effect of immaturity and prenatal asphyxia on the lung and pulmonary function of newborn lambs: the experi-

mental production of respiratory distress. Pediatrics, 35: 382 (1965).
13. Rosenthal, T. B.: The effect of temperature of the $\mathrm{pH}$ of blood and plasma in vitro. J. Biol. Chem., 173: 25 (1948)

Copyright $(1983$ International Pediatric Research Foundation, Inc. $0031-3998 / 83 / 1708-0680 \$ 02.00 / 0$
14. Rudolph, A. M. and Heyman, M. A.: Circulatory changes during growth in the fetal lamb. Circ. Res., 26: 289 (1970).

15. Schoenfisch, W. H. and Kylstra, J. A.: Maximum expiratory flow and estimated $\mathrm{CO}_{2}$ elimination in liquid-ventilated dog's lungs. J. Appl. Physiol., 34: 117 (1973).

16. Shaffer, T. H. and Moskowitz, G. D.: Demand-controlled liquid ventilation of the lungs. J. Appl. Physiol., 36: 208 (1974)

17. Shaffer, T. H., Rubenstein, D., Moskowitz, G. D., and Delivoria-Papadopoulos, M.: Gaseous exchange and acid-base balance in premature lambs during liquid ventilation since birth. Pediatr. Res., 10: 227 (1976).

18. Shaffer, T. H., Delivoria-Papadopoulos, M., Arcinue, E., Paez, P., and Dubois A. B.: Pulmonary mechanics in premature lambs during the first few hours of life. Resp. Physiol., 28: 179 (1976).

19. Shaffer, T. H., Koen, P. A., Moskowitz, G. D., Ferguson, J. D., and DelivoriaPapadopoulos, M.: Effect of positive and expiratory pressure on lung mechanics of premature lambs. Biol. Neonate, 34: 1 (1978).

20. Sivieri, E. M., Moskowitz, G. D., and Shaffer, T. H.: Instrumentation for measuring cardiac output by direct Fick method during liquid ventialtion. Undersea Biomed. Red., 8(2): 75 (1981).

21. Stahlman, M., Lequire, V. S., Young, W. C., Merrill, R. E., Birmingham, R. T., Payne, G. A., and Gray, J.: Pathophysiology of respiratory distress in newborn lambs. Am. J. Dis. Child., 108: 375 (1964).

22. West, J. B., Dollery, C. T., and Naimark, A.: Distribution of blood flow in isolated lung; relation to vascular and alveolar pressures. J. Appl. Physiol., 19: 713 (1964).

23. Zweizig, H. Z., Kuhl, D. F., Kutz, R., and Polgar, G.: Distribution of pulmonary blood flow in fetal and newborn lambs. Resp. Physiol., 8: 160 (1970).

24. Requests for reprints should be addressed to: Dr. Thomas H. Shaffer, Department of Physiology, School of Medicine, Temple University Health Sciences Center, 3420 North Broad Street, Philadelphia, Pennsylvania 19140.

25. The research leading to this paper was supported in part by Public Health Service Grant HL-22843. Fluorocarbon liquid was supplied by RIMAR, S.P.A., represented in the United States by Mercantile Development, Inc.

26. Received for publication February 24, 1982

26. Accepted for publication December $28,1982$. 